\title{
Impact of Wind Power Generation on System Operation and Costs
}

\author{
Wang Fei ${ }^{1,2, *}$, Pan Wenxia ${ }^{1}$ and Quan Rui ${ }^{1}$ \\ ${ }^{1}$ Research Center for Renewable Energy Generation Engineering Hohai University, Nanjing 210098, China \\ ${ }^{2}$ School of Electrical Engineering \& Automation, Jiangsu Normal University, Xuzhou 221116, China
}

\begin{abstract}
In this paper, a deterministic security-constrained unit commitment (SCUC) model is deployed in order to optimize generation output and allocation for spinning reserve considering different wind power dispatch modes. In this model, the scheduling of power plants takes into account a simultaneous clearing of power, reserve capacity requirement and $\mathrm{CO}_{2}$ emission and so on. Spinning reserve is modelled as an exogenous parameter which represents load uncertainty and wind power uncertainty. Special attention in the study is given to determine the impact of different dispatch modes with wind power and different levels of spinning reserve requirement on system operation and costs. The proposed model can be formulated as a mixed-integer problem (MIP) and solved in GAMS by using the CPLEX optimizer. The model is applied to a wind-fired intensive power system for three case studies. The results include the optimal spinning reserve and generator output of each generator, $\mathrm{CO}_{2}$ emission cost and cost of wind power for each case study. The results show that taking wind power as a control option can improves system operation and costs if wind generation and traditional sources generation are coordinated properly.
\end{abstract}

Keywords: Wind power, dispatch mode, reserve allocation, security-constrained unit commitment (SCUC).

\section{INTRODUCTION}

Power system operators have a number of responsibilities that focus on maintaining reliability [1,2]. The reliable operation of a power system depends on maintaining frequency at or very close to nominal levels $(50 \mathrm{~Hz}$ in China, Europe and many other areas throughout the world, $60 \mathrm{~Hz}$ in North America) [3]. However, many of the properties of the power system, including its generation output, load levels, and transmission equipment availability are both variable and unpredictable. In particular, with the advent of variable renewable generation technologies being introduced to the electric power system, the way in which the system is planned and operated may need significant changes. For instance, the characteristics of wind power technology are quite different from traditional sources of generation technology that has historically met the electricity demand [4]. The inherent variability and uncertainty of wind power generation technology increase the variability and uncertainty of the existing system and have significant effects on operation of system [5]. A variety of studies show that the varying nature of these generation sources affects the scheduling and operation of conventional power plants [6]. Therefore, power system operators often use scheduling techniques throughout the day to match generation and demand. However, the total supply of energy is different from the total demand because of variability and/or uncertainty, thus, power system operators must deploy operating reserves to correct the energy imbalance so that frequency is maintained [7].
Operating reserves are generally classified into spinning reserves and non-spinning reserves according to the North American Electric Reliability Corporation (NERC) definitions [8]. Spinning reserve is the most important resource to compensate energy imbalance. Over the past decades, much research has been done to evaluate the spinning reserve requirement. Reference [9] has done the earliest work to consider how the spinning reserve could be optimized within unit commitment (UC) problem without considering largescale wind generation integration. In recent years, a large number of entities have been investigating the way the systems with large penetration of wind generation impact reliability and costs. In [10] and [11] the impact of wind power increasing system imbalances and need for reserve capacity are studied in Nordic countries. Reference [12] builds a lowcarbon dispatch model of wind-incorporated power system considering energy-environmental efficiency. Moreover, a hybrid algorithm based on particle swarm optimization (PSO) and simulated annealing is used to obtain better solutions. Reference [13] presents a stochastic method for the hourly scheduling of optimal reserves, which takes the hourly forecast errors of wind energy and load into account. Reference [14] proposes a stochastic programming model for spinning reserve optimization in the power system with high wind power penetration, in which both load shedding cost and wind spillage cost are accounted. A risk-based reserve allocation method that accounts multiple control sub-area coordination is given in [15], and a PSO method is employed to provide a numerical solution for the problem. The tradeoff between cost and reserves provision has been emphasized by Reference [16], which determines optimal spinning reserves using an approach based on cost-benefit analysis. The proposed method can be formulated as a mixed-integer linear 
program (MILP) and solved with large-scale commercial solvers. In [17] the impacts of wind power on system operation costs and $\mathrm{CO}_{2}$ emission reduction are studied with respect to the Irish power system. In [18], the study involves how operating reserve requirements are determined with different wind energy scenario.

Although much work has been done on optimal generation output and spinning reserve determination problem, most of these studies are focused on evaluating the spinning reserve capacity requirements, and only a little work pays attention to the spinning Reserve allocation problem, while the effect of wind power on system fuel savings and $\mathrm{CO}_{2}$ emission has not been given full discussion in the UC modeling process. In this paper, the spinning reserve allocation problem is investigated for active power generation dispatch. The objective of power system operators is to minimize the expected operating cost from procurement energy and reserve in the day-ahead market, assuming a certain risk level.

The rest of this paper is organized as follows: Section 2 provides a deterministic security-constrained unit commitment model for optimal generation output and spinning reserve allocation based on cost-benefit analysis. Wind power dispatch modes, generation system and demand profile, and the performance indices used in the model are further discussed in Section 3, which is applied for three case studies of a generation system representing characteristics of China's typical wind-fired intensive power system, discussed in Section 4. The conclusion drawn from the analysis is provided in Section 5.

\section{MATHEMATICAL MODEL DESCRIPTION}

In this paper, a deterministic security-constrained unit commitment model is deployed optimizing the scheduling of power plants while meeting the electricity demand and wind power integration. A mathematical description of the optimization model is given in (1). As represented in $[19,20]$, the proposed model is formulated as a cost minimization problem using mixed integer programming.

\subsection{Objective Function}

In a restructured power system, it is assumed that the power system operator intends to minimize the total power system operating cost as follows:

$T C=\min \left\{\begin{array}{l}{\left[\sum_{t=1}^{T} \sum_{i=1}^{N G} C_{i, t}\left(P_{i, t}^{G}\right) \cdot Z_{i, t}+S U C_{i} \cdot Z_{i, t} \cdot\left(1-Z_{i, t-1}\right)\right]} \\ C_{S R}+C_{E}+C_{W}+C_{\text {curt }}^{W}+C_{\text {sthed }}^{L}\end{array}\right\}$

Where

$$
\begin{aligned}
& C_{i, t}\left(P_{i, t}^{G}\right)=B E_{i, t} \cdot P_{i, t}^{G} \\
& C_{S R}=\sum_{t=1}^{T} \sum_{i=1}^{N G} B R_{i, t} \cdot S R_{i, t}^{G} \cdot Z_{i, t} \\
& C_{E}=\sum_{t=1}^{T} \sum_{i=1}^{N G} K_{c c_{2} \text { price }} \cdot E_{i, t} \cdot P_{i, t}^{G} \cdot Z_{i, t}
\end{aligned}
$$

$$
\begin{aligned}
& C_{W}=\sum_{t}^{T} \lambda_{W} \cdot P_{t}^{W} \\
& C_{\text {curt }}^{W}=\sum_{t}^{T} \lambda_{\text {curt }} \cdot W_{t}^{\text {curt }} \\
& C_{\text {shed }}^{L}=\sum_{t}^{T} \lambda_{\text {shed }} \cdot Q_{t}^{\text {shed }}
\end{aligned}
$$

In the objective function, the total expected operation cost $(T C)$ associated with operating cost $(O C)$ of conventional generating unit, total spinning reserve cost $\left(C_{S R} \mathrm{C}_{\mathrm{SR}}\right)$, total $\mathrm{CO}_{2}$ emission cost $\left(C_{E}\right)$, operating cost of wind power $\left(C_{W}\right)$, wind curtailment, and demand shedding needs to be minimized over all problem variables. The operating cost $(O C)$ consists of summation of generation costs of committed units and start-up costs of previously uncommitted units.

In power systems containing wind farms, an additional part of spinning reserve capacity is needed to balance wind power prediction errors and short-term fluctuations so that the system can run reliably. Therefore, spinning reserve considered in this model consists of two parts: the traditional spinning reserve determined from uncertainty of load forecast; and the spinning reserve resulting from variability of wind power. The traditional spinning reserve and additional spinning reserve considering wind power in each hour can be respectively computed as a fixed percentage of system hourly load and wind power.

Based on the premise of the low-carbon economy, the relation between generation and $\mathrm{CO}_{2}$ emission of various power plants is formulated, and the power system optimization model takes carbon emissions into account. As wind power participates in UC with conventional units in model, the objective function is associated with the cost of wind generation.

The last two terms of the objective function are compensation cost of wind power curtailment and demand shedding, as a part of operating reserve. Setting the curtailment and demand shedding has an important impact on the feasibility of the model.

\subsection{Model Constraints}

The objective function must be minimized subject to a number of reliability constraints. In this section, the constraints for the problem are given by active power balance of the system, unit capacity constraint, ramp rate constraint for conventional units, spinning reserve requirements constraint, minimum up- and downtimes constraints [21,22].

$$
\begin{aligned}
& \sum_{i}^{N G} P_{i, t}^{G} \cdot Z_{i, t}+P_{t}^{W}=Q_{t} \\
& Q_{t}=q_{t}-Q_{t}^{\text {shed }} \\
& P_{t}^{W}=W_{t}-W_{t}^{\text {curt }}
\end{aligned}
$$


$P_{i}^{\min } \cdot Z_{i, t} \leq P_{i, t}^{G} \leq P_{i}^{\min } \cdot Z_{i, t}$

$0 \leq P_{t}^{W} \leq W_{t}$

$P_{i, t}^{G}-P_{i, t-1}^{G} \leq \Delta P R_{i} \cdot \Delta T$

$P_{i, t}^{G}-P_{i, t-1}^{G} \geq-\Delta P R_{i} \cdot \Delta T$

$S R_{i, t}^{G}=\min \left(\Delta P R_{i} \cdot \Delta T, P_{i}^{\max } \cdot Z_{i, t}-P_{i, t}\right)$

$\sum_{i}^{N G} S R_{i, t}^{G}=S R_{t}^{L}+S R_{t}^{W}$

$Z_{i, t}-Z_{i, t-1}-Z_{i, t+k} \leq 0$

$\forall k \in\left[1,2, \ldots\right.$, mut $\left._{i}-1\right]$

$Z_{i, t-1}-Z_{i, t}+Z_{i, t+k} \leq 1$

$\forall k \in\left[1,2, \ldots\right.$, mut $\left._{i}-1\right]$

It can be seen from Equation (1) to Equation (12) that the proposed model is a deterministic security-constrained unit commitment model, including conventional energy production, spinning reserve provision, $\mathrm{CO}_{2}$ emission, wind power injection, wind curtailment, and demand shedding. This model aims to determine the optimal scheduling of power plants and reserve allocation to meet the demand at the lowest costs, and is widely used for the investigation of the impact of wind generation on the power system operation. The proposed model can be formulated as a Mixed Integer Problem (MIP) and solved using CPLEX12.5 under GAMS [23].

\section{WIND ENERGY UTILIZATION STUDIES}

\subsection{Wind Power Dispatch Modes}

This section considers wind power dispatch modes in day-ahead scheduling with a focus on the problems proposed by wind power variability to the overall power system operation. Due to the positive role of wind power in emission reduction and fuel saving, policy incentives are used in many countries to promote wind in power systems as a priority $[24,25]$. This paper considers two scenarios for wind dispatch priority:

1) Guaranteed wind power dispatch: Wind power is fully dispatched as long as the operational security and controllability can be ensured.

2) Privileged wind power dispatch: Wind power is given priority dispatch, but wind curtailment can be used as a control option of wind generation in day-ahead unit commitment whenever necessary.

Three case studies are presented to study the relationship between generation output and spinning reserve allocate considering wind power dispatch modes.
Case 1: Power plant scheduling without wind power integration.

Case 2: Power plant scheduling with wind power integration and guaranteed wind power dispatch.

Case 3: Power plant scheduling with wind power integration and privileged wind power dispatch.

\subsection{Generation System and Demand Profile}

The generation model used for these case studies represents a conceptual power system, roughly based on Inner Mongolia Tongliao. However, a few adaptations are done in order to limit complexity and generalize the model. Technical parameters of the different power plants have been obtained from the reference $[26,27]$ due to a lack of conventional unit data from China, which final values used in the model are given Appendix A. The generation system consists of 21 power plants including six coal-fired steam turbine power plants, four combined-cycle gas turbines, five open-cycle gas turbines and six oil-based internal combustion engine power plants.

In this paper, In order to obtain a correct order of procuring, the economic performance of various power plants is investigated and compared. The data of these costs are derived from those published in $[28,29]$. The fuel cost is assumed to be $2.63 € / \mathrm{GJ}, 8.43 € / \mathrm{GJ}, 8.43 € / \mathrm{GJ}$ and $13.21 € / \mathrm{GJ}$, which is respectively represent STEAM, CCGT, GT and ICE power plant. The $\mathrm{CO}_{2}$ content per fuel is derived from [30] and a forward $\mathrm{CO}_{2}$ emission price is set relatively high at 38 $€ /$ ton. Accordingly, the variable generation costs are calculated by means of the fuel cost and $\mathrm{CO}_{2}$ emission cost for each power plant. It is assumed that the spinning reserve cost of each generator is $40 \%$ of unit generation cost. The hourly spinning reserve for load and wind power uncertainty respectively are assumed to be $10 \%$ of hourly load and $20 \%$ of hourly wind power.

Simulations are performed with forecast wind power and system demand profiles from Inner Mongolia Power Group. These profiles are rescaled taking into account unavailability of generation assets and demand growth towards 2020. The forecast wind power and average demand profiles are illustrated in Fig. (1) and Fig. (2). The installed wind power capacity represents $26 \%$ of the installed capacity. The generation cost of wind power is set to be $80 € / \mathrm{MWh}$.

\subsection{System Performance Indices}

The following system performance indices considered in this paper are used to compare different dispatch modes.

1) Unit Operation Cost of the System $(€ / \mathrm{MWh}) c_{t c}$

$c_{t c}=\frac{T C}{E_{s d}}$

Where $T C$ is given in Equations (1) and $E_{s d}$ is given as $E_{s d}=\sum_{t=1}^{T} Q_{t}$. 


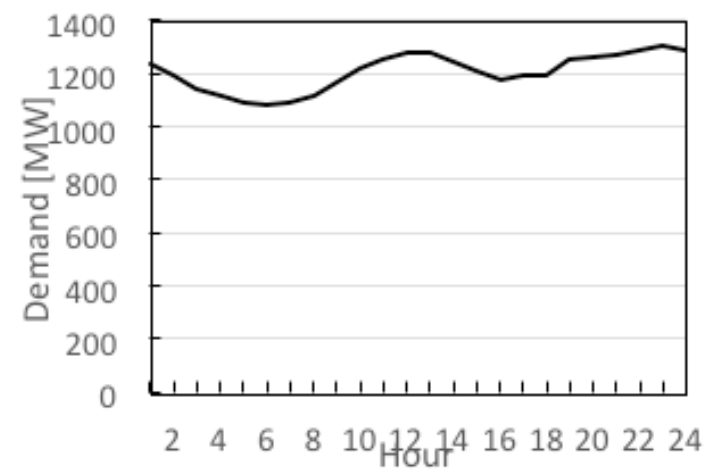

Fig. (1). Demand profile for the simulation day.

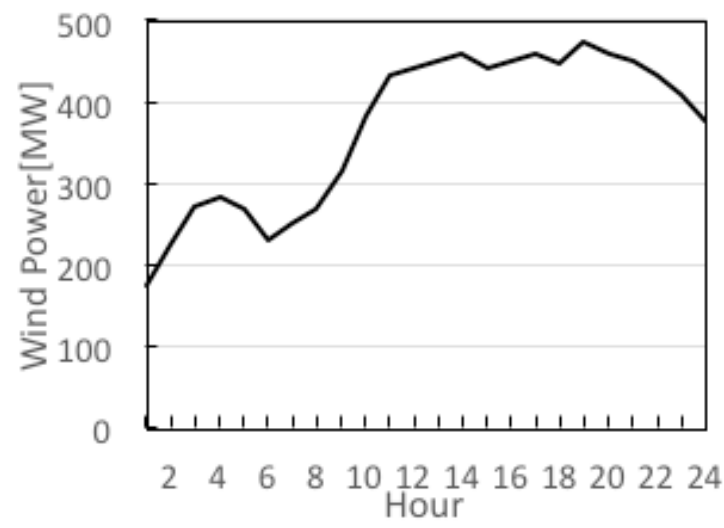

Fig. (2). Wind power profile for the simulation day.

2) Total Generation Cost of Conventional Units $(€) \mathrm{C}_{\mathrm{PG}}$ $C_{P G}$

$C_{P G}=\sum_{t=1}^{T} \sum_{i=1}^{N G} C_{i, t}\left(P_{i, t}^{G}\right) \cdot Z_{i, t}$

3) Unit Generation Cost of Conventional Units

$\left(€ /\right.$ Mwah) $c_{p g}$

$c_{p g}=\frac{C_{P G}}{E_{P G}}$

Where $E_{P G}$ is given by

$E_{P G}=\sum_{i=1}^{T} \sum_{i=1}^{N G} P_{i, t}^{G}$

4) Unit Spinning Reserve Cost of the System ( $€ / M W h)$ $r_{u}$

$r_{u}=\frac{C_{S R}}{\sum_{t=1}^{T}\left(S R_{t}^{L}+S R_{t}^{W}\right)}$

5) Unit $\mathrm{CO} 2$ Emission of the System(ton/MWh) $e_{u}$
$e_{u}=\frac{C_{E}}{E_{s d} \cdot K_{c c_{2} p r i c e}}$

6) Wind Energy Average Use Rate (\%) $\eta_{W}$

$\eta_{W}=\frac{E_{W}^{\text {avail }}-E_{W}^{\text {curt }}}{E_{W}^{\text {avail }}} \times 100 \%$

Where $E_{W}^{\text {avail }}=\sum_{t=1}^{T} W_{t}, E_{W}^{\text {curt }}=\sum_{t=1}^{T} W_{t}^{\text {curt }}$.

In order to ensure a feasible solution, demand shedding is implemented as a last resort measure, i.e. at an elevated cost. Compensation cost demand shedding is assumed to be 10000 $€ / M W h$. Different compensation cost of wind power curtailment $\left(\lambda_{\text {curt }}\right)$ settings are used as indicators for different wind power dispatch priorities. In reality, this curtailment cost may depend on the specific policies applied in a control zone. For case $2, \lambda_{\text {curt }}$ is a very large number, i.e. $500 € / \mathrm{MWh}$, so as to discourage wind power curtailment and thus ensure guaranteed wind power dispatch. For case 3, $\lambda_{\text {curt }}$ is 0 , so that wind power is curtailed whenever necessary without having to worry about the compensation. 
Table 1. System Performance Indices of Three Cases.

\begin{tabular}{|c|c|c|c|c|c|c|}
\hline Case & $\boldsymbol{C}_{\boldsymbol{P G}}$ & $\boldsymbol{c}_{\boldsymbol{p g}}$ & $\boldsymbol{e}_{\boldsymbol{u}}$ & $\boldsymbol{r}_{\boldsymbol{u}}$ & $\boldsymbol{c}_{\boldsymbol{t c}}$ & $\boldsymbol{\eta}_{\boldsymbol{w}}$ \\
\hline \hline 1 & 1947217.62 & 67.0968 & 0.69354 & 39.41914 & 98.0541 & $0.00 \%$ \\
\hline 2 & 1401888.77 & 69.4795 & 0.51545 & 42.27576 & 99.6848 & $100 \%$ \\
\hline 3 & 1367085.07 & 66.6948 & 0.51765 & 36.65366 & 97.0348 & $96.26 \%$ \\
\hline
\end{tabular}

As elevated costs discourage the use of these options in the model, which are set to keep focus on the flexibility of the conventional energy generation system.

\section{SIMULATION RESULTS AND DISCUSSIONS}

In this section, the presented deterministic security constrained unit commitment model is used to determine the impact of different dispatch modes with wind power and different levels of reserve requirement on system operation and costs. This is an important issue as we have seen that the generation outputs and reserve capacity allocation change when wind power is added with different dispatch modes.

\subsection{Simulation Results1: Impact of the Generation Costs and $\mathrm{CO}_{2}$ Emissions}

The objective functions, the system performance indices of three cases, are summarized in Table 1. In Case 1, all the loads are supplied by only conventional generators with spinning reserves from load uncertainty. In comparing the system indices in Case 1 and Case 2, it can be seen that $C_{P G}$ and $e_{u}$ following wind power integration in power systems leads to significant reductions and additional indices, i.e. $c_{p g}, r_{u}$ and $c_{t c}$ with increase in unit cost. This is explained that a CCGT and partial peak power plant would be replaced by wind power leading to reduce fuel and emission costs. Furthermore, the increment of unit cost $\left(c_{p g}, r_{u}\right.$ and $\left.c_{t c}\right)$ in Case 2 compared to Case 1 reflects the impact of two factors. One is the reduced efficiency of the coal-fired and gas-fired units in accommodating the variability of wind power when giving wind power guaranteed dispatch. The other is the extra spinning reserve procurement to meet the variability of wind power.

Comparison of the system indices in Case 2 (guaranteed wind power dispatch) and Case 3 (privileged wind power dispatch) shows that, though the wind energy use rate $\left(\eta_{w}\right)$ is smaller in case 3 , in which wind curtailment is executed whenever necessary, the system performance indices such as the total cost of the conventional units $\left(C_{P G}\right)$, the unit generation cost of conventional units $\left(c_{p g}\right)$, the unit reserve cost of system $\left(r_{u}\right)$ and unit operation cost of the system $\left(c_{t c}\right)$, outperformed those with a slight increase in unit $\mathrm{CO}_{2}$ emissions costs $\left(e_{u}\right)$ in case 2 . These indicate that in wind-fired intensive power systems, wind curtailment should be used as a control option to improve total system operation if variable renewable generation and traditional sources generation are coordinated properly rather than only when system security is threatened.
As can be seen, all performance indices of Case 3 are better than those of Case 1. The results of comparison show that variable renewable generation and traditional sources generation are coordinated properly, leading to better system economies and $\mathrm{CO}_{2}$ emissions reduction in Case 3, even with wind curtailment.

\subsection{Simulation Results 2: Impact of Generation and Re- serve Capacity Schedule}

The generation and reserve capacity schedule of committed units of case studies 1-3 are shown in Figs. (3-5), respectively. We can observe that the coal-fired power plants are operated as base load, the combined-cycle gas turbines as load following. And the GTS and ICES are mainly operated as peak power plant in the models, but it is difficult to see due to the low output level in Figs. (3-5) (Left). Fig. (3). shows the impact of a varying spinning reserve requirement from uncertainty of load forecast on system operation in Case 1 without wind power, spinning reserves are mainly provided from the CCGT and the coal-fired generating units. When spinning reserve requirements exceeding $120 \mathrm{MW}$ capacity for higher load and reserve capacities, operational flexibility is no longer sufficient and an additional CCGT power plant is scheduled to assist in delivering the requested amount of reserves from 10h AM. The three CCGTS are now operated at partial load, resulting in efficiency losses. Also, between oh-4h and 8h-9h, additional GT and ICE peak power plants are scheduled at partial load in order to provide additional reserves. Finally, sometimes, the sixth coal-fired power plant participates in the provision of reserves though output reductions.

By comparing Cases 1-2 generations and reserve capacity schedule, in which the wind power participates in UC with wind power forecast. In Case 2, simulation results show that is replace the CCGT which is scheduled to provide generation output with wind power. This is illustrated in Fig. (4) (Left) this represents a simulation with guaranteed wind power dispatching. The total spinning reserves are mainly provided from the coal-fired generating units and the CCGT. Furthermore, two gas-fired peak plants and an ICE peak plants are scheduled to provide the final reserve requirements. Both coal-fired power plants and CCGTS are now operated at partial load, resulting in efficiency losses and increment of unit generation costs $\left(c_{t c}, c_{p g}\right)$ due to extra spinning reserve procurement to meet variability of wind power. We can see that the trend of partial load increases significantly between $10 \mathrm{~h}$ and $24 \mathrm{~h}$ due to high wind. 

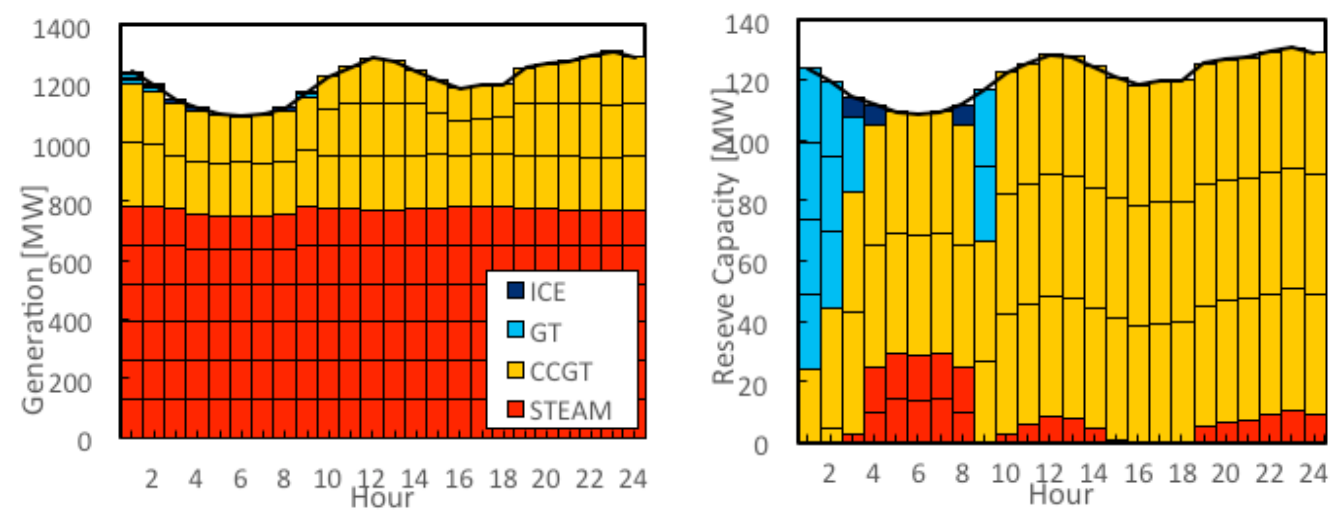

Fig. (3). Generation and reserve capacity schedule for case 1.
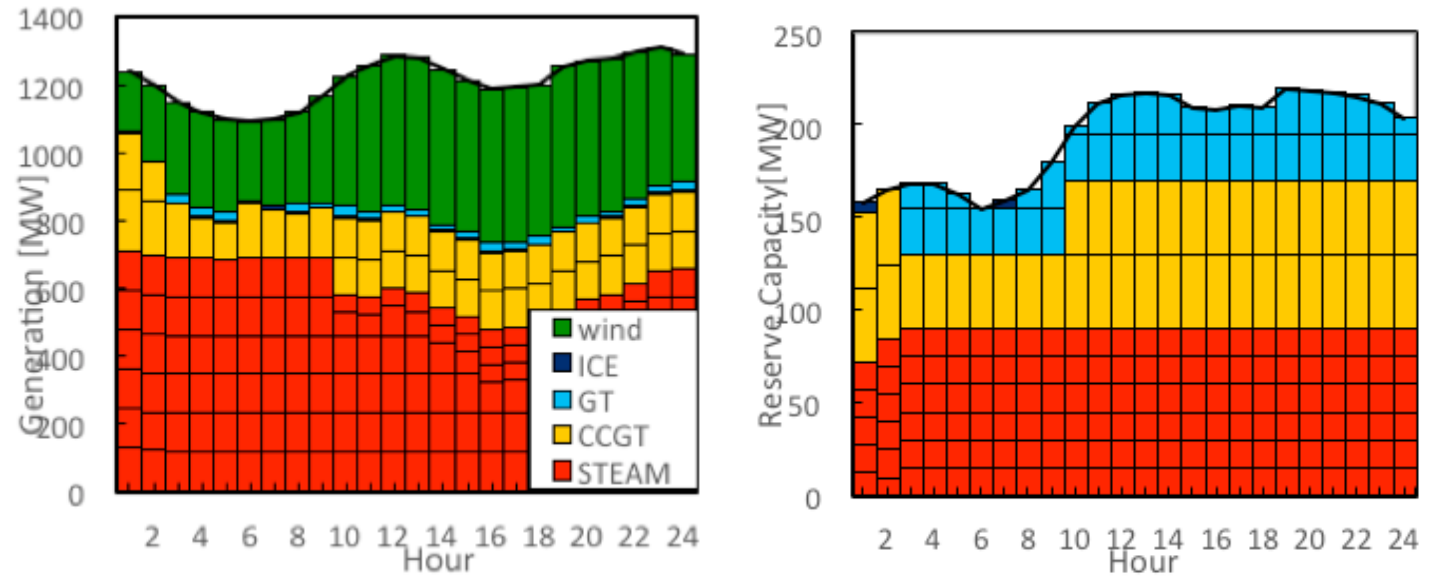

Fig. (4). Generation and reserve capacity schedule for case 2.
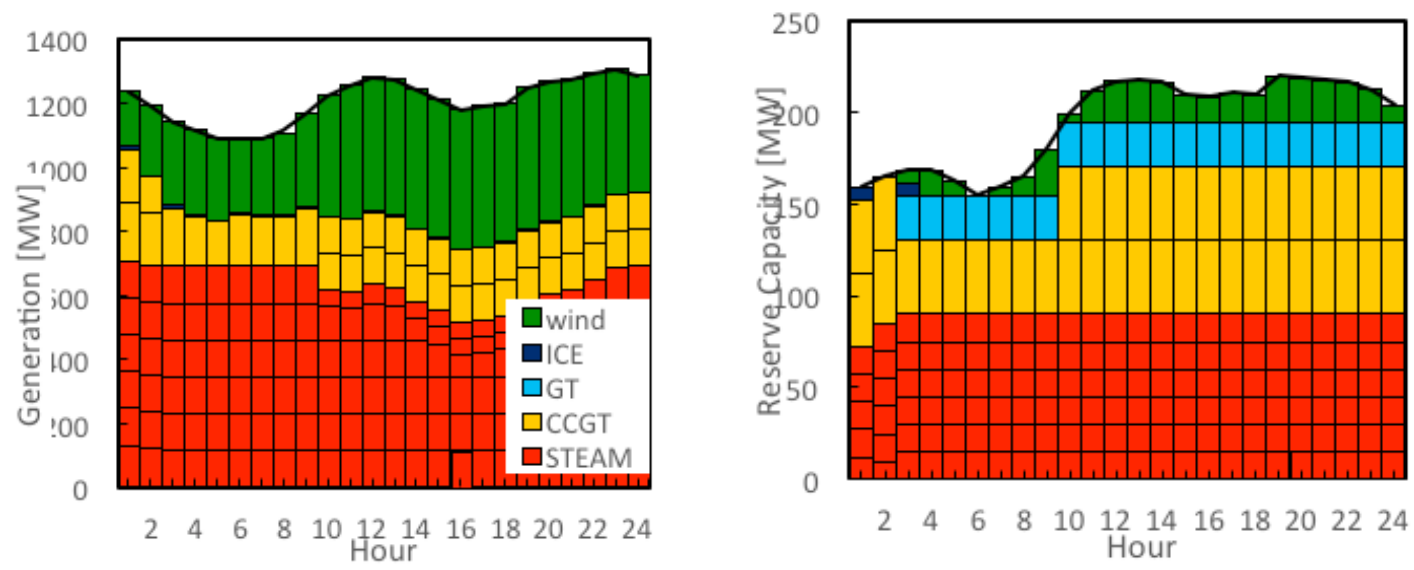

Fig. (5). Generation and reserve capacity schedule for case 3.

It is illustrated in Fig. (5). for Case 3. Simulation results of Case 3 show that is wind power curtailment can be taken as a control option to improve system economics and $\mathrm{CO}_{2}$ emission reduction when wind power participates in the UC and wind power is given privileged dispatch. Simulation results show that it is better to replace the gas-fired peak power plant to provide reserve capacity with wind power sometimes. The model assesses that it is cheaper to provide this capacity with wind power. In contrast, replacing the se-

cond gas-fired peak power plant would however be too expensive as generator provides $25 \mathrm{MW}$ reserve capacity.

\section{CONCLUSION}

In this contribution, a unit commitment model is deployed with spinning reserve requirements in order to study the impact of a joint demand for generation and reserve capacity on system operation and costs with special attention to 
different wind power dispatch modes. The demand for reserves is modelled as an exogenous parameter which is assumed to be decomposed into two parts, i.e., the traditional spinning reserve associated with uncertainty of load forecast and an additional part of spinning reserve capacity to respond to the wind farm power variability. Optimal wind power dispatch and spinning reserve allocation were obtained. With different wind power dispatch priorities and corresponding UC studies, the impact of wind power and the demand for reserves on system operation and costs are presented with more clarity. The study's main conclusions are as follows:

1) With wind power being introduced to the conventional electric power system, the way which the system is scheduled and operated may need significant changes. More focus should be given to assessing impact of increasing reserve requirements and variability of wind power on power plant scheduling. Thought wind power itself is emission and fuel free, the negative impacts it has on conventional generator fuel consumption and emission if variable renewable generation and traditional sources generation are not coordinated properly. One is the reduced efficiency of the conventional generator in accommodating the variability of wind power when giving wind power guaranteed dispatch. The other is the extra spinning reserve procurement to meet the wind power variability.
2) When wind power becomes a reliable provider of reserve capacity in wind-fired intensive power systems, the use of privileged wind power dispatch, in which wind curtailment can lead to the achievement of better system operation costs than guaranteed wind power dispatch.

3) Although no fundamental technical objections are present to exclude wind power from participating in the reserve market, when the operational flexibility of system is no longer sufficient and wind power should be considered as a spinning reserve provider taking wind power curtailment as a control option. It can improve system economies and $\mathrm{CO} 2$ emission reduction.

\section{CONFLICTS OF INTEREST}

The authors confirm that this article content has no conflicts of interest.

\section{ACKNOWLEDGEMENTS}

The author greatly thanks the editor and the reviewers for their valuable comments and suggestions. This study was supported by National Natural Science Foundation of China (NO.51377047).

\section{APPENDIX A}

Table 2. Technical parameters of conventional generating units.

\begin{tabular}{|c|c|c|c|c|}
\hline Units (\#) & 6 & 4 & 5 & 6 \\
\hline Max. Gen. Capacity[MW] & 130 & 220 & 37.5 & 16.7 \\
\hline Ramp Rate [MW/min] & 3 & 8 & 5 & 5 \\
\hline Min on time $[\mathrm{h}]$. & 8 & 4 & 1 & 1 \\
\hline Min off time [h.] & 5 & 4 & 1 & 1 \\
\hline
\end{tabular}

STEAM: steam power plants, CCGT: combined-cycle gas turbines, GT: open-cycle gas turbines, ICE: internal combustion engine

\section{NOMENCLATURE}

$i \quad=$ Index of conventional units

$t \quad=$ Index of time periods $(\mathrm{h})$

$N G=$ Number of conventional units

$T=$ The simulation periods (h)

$T C=$ Total expected operation cost $(€)$
$C_{i, t}=$ Generation cost of conventional unit $i$ in period $t$ $(€)$

$Z_{i, t}=$ Binary variables, commitment of unit $i$ in period $t$ (1: on-line; 0 : off-line)

$P_{i, t}^{G}=$ Generation output of conventional $\mathrm{t}$ unit $i$ in period $t(\mathrm{MW})$ 
$S U C_{i}=$ Start-up cost of conventional unit $i$ in period $t(€)$

$B E_{i, t}=$ Unit generation cost of conventional unit $i$ in period $t(€ / \mathrm{MWh})$

$C_{S R}=$ Total spinning reserve cost $(€)$

$B R_{i, t}=$ Unit spinning reserve cost of conventional unit $i$ in period $t(€ / \mathrm{MWh})$

$S R_{i, t}^{G}=$ Spinning reserve of conventional unit $i$ in period $t$ (MW)

$C_{E}=$ Total $\mathrm{CO}_{2}$ emission cost $(€)$

$K_{c 0_{2} \text { price }}=\mathrm{CO}_{2}$ emission price $(€ /$ ton $)$

$E_{i, t}=$ Average $\mathrm{CO}_{2}$ emission conventional unit $i$ in period $t(\mathrm{~kg} / \mathrm{MWh})$

$C_{W} \quad=$ Total cost of wind generation $(€)$

$C_{\text {curt }}^{W}=$ Total compensation cost of wind power curtailment during the simulation period $T(€)$

$C_{\text {shed }}^{L}=$ Total compensation cost of demand shedding during the simulation period $T(€)$

$\lambda_{W}=$ Unit cost of wind generation $(€ / \mathrm{MWh})$

$P_{t}^{W} \quad=$ Average wind power injection in period $t(\mathrm{MW})$

$W_{t} \quad=$ Average wind power predicted output in period $t$ (MW)

$\lambda_{\text {curt }}=$ Compensation cost wind power curtailment $(€ / \mathrm{MWh})$

$W_{t}^{\text {curt }}=$ Average wind power curtailment in period $t(\mathrm{MW})$

$\lambda_{\text {shed }}=$ Compensation cost demand shedding $(€ / \mathrm{MWh})$

$Q_{t}^{\text {shed }}=$ Average demand shedding in period $t(\mathrm{MW})$

$Q_{t} \quad=\quad$ Average off-take in period $t(\mathrm{MW})$

$q_{t} \quad=$ Average electricity demand in period $t(\mathrm{MW})$

$P_{i}^{\min }=$ Minimum output level generating unit $i(\mathrm{MW})$

$P_{i}^{\max }=$ Maximum output level generating unit $i(\mathrm{MW})$

$\Delta P R_{i}=$ Unit ramp rate of conventional unit $I(\mathrm{MW} / \mathrm{min})$

$\Delta T=$ Time duration, where $\Delta T$ is adjusted to $5 \mathrm{~min}$ in this paper according to their response time for frequency restoration reserve
$S R_{t}^{L}=$ Spinning reserve capacity demand due to load uncertainty in period $t(\mathrm{MW})$

$S R_{t}^{W}=$ Spinning reserve capacity demand due to wind power uncertainty in period $t$ (MW)

$m d t_{i}=$ Minimum down time of generating unit $i(\mathrm{~h})$

$m u t_{i}=$ Minimum up time of generating unit $i$

$E_{s d}=$ The total off-take electricity demand of the system during the simulation period $T(\mathrm{MWh})$

$c_{t c}=$ Unit operation cost of the system $(€ / \mathrm{MWh})$

$C_{P G}=$ Total generation cost of conventional units during the simulation period $T(€)$

$c_{p g}=$ Unit generation cost of conventional units during the simulation period $T(€ / \mathrm{MWh})$

$E_{P G}=$ The total electricity generated by conventional unit during the simulation period $T(\mathrm{MWh})$

$r_{u} \quad=$ Unit spinning reserve cost of the system during the simulation period $T(€ / \mathrm{MWh})$

$e_{u}=$ Unit $\mathrm{CO}_{2}$ emission of the system during the simulation period $T$ (ton/MWh)

$\eta_{W} \quad=$ Wind energy average use rate $(\%)$

$E_{W}^{\text {aval }}=$ Total available wind energy during the simulation period $T$ (MWh)

$E_{W}^{c u r t}=$ Total curtailed wind energy during the simulation period $T(\mathrm{MWh})$

\section{REFERENCES}

[1] A.J. Wood and B.F. Wollenberg, Power Generation Operation and Control, New York: John Wiley \& Sons, 1996.

[2] P. Kundur, Power system stability and control, New York: McGraw-Hill, 1994.

[3] GE Energy. Frequency response study final draft. Prepared for California ISO, November 2011.

[4] B. Karki, Operating Reserve assessment of wind integrated power systems, PhD thesis. University of Saskatchewan. Department of Electrical Engineering. 2010.

[5] J. King, B. Kirby, M. Milligan, et al. Operating reserve reductions from a proposed energy imbalance market with wind and solar generation in the western interconnection. Prepared for the National Renewable Energy Laboratory. 2012. NREL/TP-5500-54660.

[6] B. C. Ummels, M. Gibescu, E. Pelgrum, W. Kling, and A. Brand, "Impacts of Wind Power on Thermal Generation Unit Commitment and Dispatch," IEEE Transactions on Energy Conversion, vol. 22, no. 1,pp. 44-51, March 2007.

[7] E. Ela, M. Milligan, B. Kirby, Operating reserves and variable generation. Prepared for the National Renewable Energy Laboratory. 2011. NREL/TP-5500-51978.

[8] Y. Rebours, D. Kirschen, M. Trotignon, et al. "Asurvey of frequency and voltage control ancillary services-Part I: Technical Fea- 
tures," IEEE Trans. Power Syst. vol. 22, no. 1, pp.350-357. February 2007.

[9] H. B. Gooi, D. P. Mendes, K. R. W. Bell, and D. S. Kirschen, "Optimal scheduling of spinning reserve," IEEE Trans. Power Syst., vol. 14, no.4, pp. 1485-1492, November 1999.

[10] H. Holttinen, "Impact of hourly wind power variations on the system operation in the Nordic countries," Wind Energy, vol. 8, no. 2, pp. 197-218, April 2005.

[11] E. Ela, B. Kirby, E. Lannoye, et al. "Evolution of operating reserve determination in wind power integration studies," IEEE Power \& Energy Society General Meeting, 2010, pp. 25-29.

[12] D. J. Chen, Q. W. Gong, B. C. Zou,"A low-carbon dispatch model in a wind power integrated system considering wind speed forecasting and energy-environmental efficiency," Energies. vol. 5, pp. 1245-1270. September 2012.

[13] C. Sahin, F. Shahidehpour, I. Erkmen, "Allocatin of hourly reserve versus demand response for security- constrained scheduling of stochastic wind energy," IEEE Trans. Energies. vol. 4, pp. 219228. January 2013.

[14] J. M. Morales, A. J. Conejo, R.J. Perez, "Economic valuation of reserves in power systems with high penetration of wind power," IEEE Trans. Power Syst. vol. 24, pp. 900-910. April 2009.

[15] J. H. Chen, W. C. Wu, B.M. Zhang, "A Spinning reserve allocation method for power generation dispatch accommodating large-scale wind power integration," IEEE Trans. Energies. Vol. 6, pp. 53575381.October 2013.

[16] K. Afshar, M. Ehsan, F. M. Fotuhi, "Cost-benefit analysis and MILP for optimal reserve capacity determination in power system," Applied Mathematics and Computation, vol. 196 pp.752-761. March 2008 .

[17] P. Meibom, R. Barth, B. Hasche, "Stochastic optimization model to study the operational impacts of high wind penetrations in Ireland," IEEE Trans. Power Syst. vol. 26, pp. 1367-1379. September 2010.

[18] D. Corbus, M. Milligan, E. Ela, Eastern wind integration and transmission study, Prepared for the National Renewable Energy Laboratory, 2009. NREL/CP-550-4650.

[19] M. Ortega-Vazquez, D. Kirschen, "Optimizing the spinning reserve requirements using a cost/benefit analysis," IEEE Trans. Power Syst. Vol.22, pp. 24-33. February 2007.
[20] N. Padhy, "Unit commitment-a bibliographical survey," IEEE Trans. Power Syst., Vol.19, pp. 1196-1205. May 2004.

[21] K. De-Vos, Sizing and allocation of operation reserves following wind power integration. $\mathrm{PhD}$ Thesis, University of Leuven, Faculty of Engineering, Department of Electrical Engineering. 2013.

[22] E. Delarue, Modeling electricity generation systems: development and application of electricity generation optimization and simulation models, with particular focus on CO2-emissions. $\mathrm{PhD}$ Thesis, University of Leuven. Department of Mechanical Engineering. 2009.

[23] GAMS - General algebraic modeling system. CPLEX Solver Manual. 2012. Available at: http://www.gams.com. Last consulted on $10 / 03 / 20$.

[24] C. Klessmann, C. Nabe, K. Burges, "Pros and cons of exposing renewables to electricity market risks-a comparison of the market integration approaches in Germany, Spain, and the UK," Energy Policy, vol. 36, pp. 3646-3661, October 2008.

[25] C. X. Wang, Z. X. Lu, Y. Qiao, "A consideration of the wind power benefits in day-ahead scheduling of wind-coal intensive power systems," IEEE Trans. Power Syst, vol. 28, pp. 236-245, February 2013.

[26] EAC - Electricity authority of Cyprus, generation system data 2012. Available at: http://www.eac.com.cy/. Last consulted on 23/02/2012.

[27] K. De Vos, J. Driesen, "Impact of wind power reserve requirements on system operation and costs," IAEE European Conference, Venice, Italy, pp. 9-12, September 2012.

[28] IEA-International Energy Agency, World Energy Outlook. Paris Cedex, France, 2010, p. 738.

[29] R. Tarjanne, A. Kivistö, Comparison of electricity generation costs. Lappeenranta University of Technology Research Report, 2008.

[30] IEA-International Energy Agency, $\mathrm{CO} 2$ emissions from fuel combustion highlights. Available at: http:// www. iea.org/co2highlights. 2010 .

(C) Fei et al.; Licensee Bentham Open.

This is an open access article licensed under the terms of the Creative Commons Attribution Non-Commercial License (http://creativecommons.org/licenses/by$\mathrm{nc} / 3.0 /$ ) which permits unrestricted, non-commercial use, distribution and reproduction in any medium, provided the work is properly cited. 